\title{
PERBANDINGAN ATENUASI PERCEPATAN BATUAN DASAR DENGAN FUNGSI ATENUASI Mc Guire (1977), Campbell (1981), Idriss (1991) dan Ambraseys (1995)
}

\author{
Muhammad Ramadhan ${ }^{1)}$, Muhammad Irfan Sigani $^{2)}$, Ezral Dwi Prayogi ${ }^{3)}$ \\ ${ }^{x}$ 1),2),3) Program Studi Teknik Sipil, Universitas Muhammadiyah Sorong Email : \\ ramadhanadam1402@gmail.com
}

\begin{abstract}
Abstrak
Atenuasi getaran tanah (ground motion attenuation) adalah proses/ rumusan yang mana suatu gerakan tanah Y akibat gempa (percepatan, kecepatan, simpangan) ataupun intensitas gempa akan mengecil pada jarak yang semakin jauh dari sumber gempa, akibat redaman/ penyera-pan energi oleh massa batuan/tanah. Secara matematis, atenuasi getaran tanah adalah suatu hubungan antara jarak, $\mathrm{R}$ (episenter, jarak terdekat, jarak hipo-senter) dengan parameter gempa Y (percepatan, kecepatan, simpangan, intensitas gempa, ukuran gempa). Dari ketiga grafik diatas dapat disimpulkan bahwa nilai ground acc akan semakin kecil terhadap jarak epicenter. Hal ini sesuai dengan factor yang mempengaruhi atenuasi salah satunya yaitu jarak ke site (jarak episenter, jarak terdetak, jarak hiposenter).
\end{abstract}

Kata Kunci : Kurva Hazard, Perbandingan Atenuasi, Fungsi Atenuasi

\section{Pendahuluan}

Atenuasi getaran tanah (ground motion attenuation) adalah proses/ rumusan yang mana suatu gerakan tanah Y akibat gempa (percepatan, kecepatan, simpangan) ataupun intensitas gempa akan mengecil pada jarak yang semakin jauh dari sumber gempa, akibat redaman/ penyera-pan energi oleh massa batuan/tanah

Secara matematis, atenuasi getaran tanah adalah suatu hubungan antara jarak, R (episenter, jarak terdekat, jarak hipo-senter) dengan parameter gempa Y (percepatan, kecepatan, simpangan, intensitas gempa, ukuran gempa).

a. Faktor-faktor yang mempengaruhi atenuasi : 
- Ukuran gempa $\left(\mathrm{M}_{\mathrm{L}}, \mathrm{M}_{\mathrm{S}}, \mathrm{Mb}, \mathrm{M}_{\mathrm{w}}\right)$

- Jarak ke site (jarak episenter, jarak terdetak, jarak hiposenter)

- Mekanisme sumber gempa

- Pengaruh kondisi site

b. Fungsi uatama dari magnitudo gempa M dan jarak R (Abrahamson \& Silva, 2007)
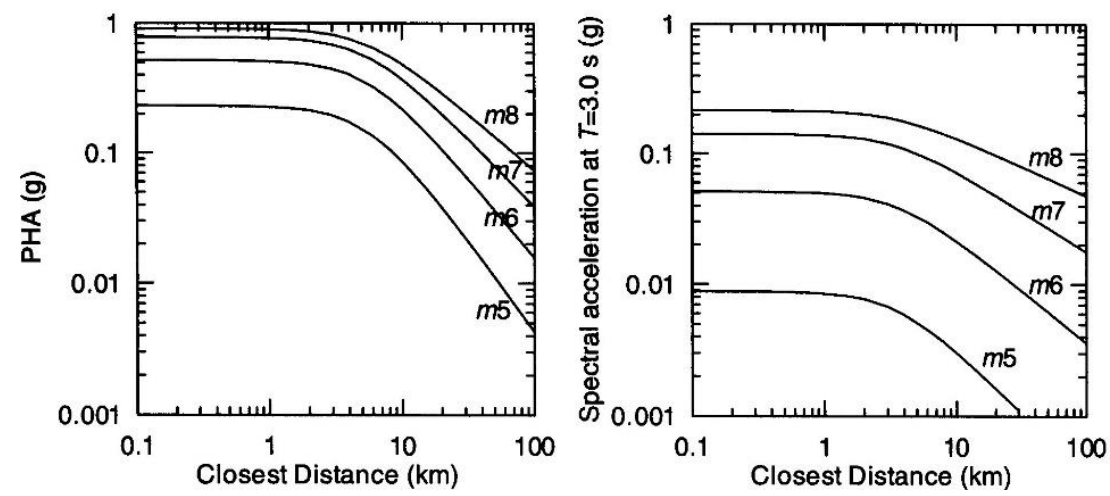

- Semakin besar magnitudo gempa maka Peak Horizontal Acceleration (PHA) dalam gravitasi bumi akan semakin besar

- Semakin jauh cosest distance R maka PHA akan semakin kecil (akibat redaman/ serapan energi tanah/batuan)

c. Sifat Atenuasi :

- Nilai maksimum parameter gerakan tanah (percepatan, kecepatan, sim-pangan, intensitas) umumnya terdistribusi secara lognormal (skala loga-ritma baik bilangan dasar 10 maupun natural logarithmic $\ln$ ) terhadap jarak sumber gempa ke pencatat gempa. Oleh karena itu umumnya dibuat regresi linear, misalnya untuk atenuasi pecercepatan (Y) dalam bentuk $\log (\mathrm{Y})$ atau $\ln (\mathrm{Y})$ dan bukannya $\mathrm{Y}$.

- $\log (\mathrm{Y})$ atau $\operatorname{Ln}(\mathrm{Y})$ dipengaruhi secara langsung/linier oleh ukuran gem-pa, M. Hal ini berarti bahwa setiap kenaikan ukuran gempa $\mathrm{M}$ akan berpengaruh secara langsung/linier terhadap $\log (\mathrm{Y})$ atau $\ln (\mathrm{Y})$,

- Amplitudo gelombang bodi menurun dengan rate $1 / \mathrm{R}$ (attenuation rate) sedangkan amplitudo gelombang permukaan kecepatan menurun dengan rate $1 / \square \mathrm{R}$, dengan $\mathrm{R}$ adalah jarak episenter dalam $\mathrm{km}$ 
- Energi yang menyebar dari pusat gempa akan semakin berkurang akibat redaman material tanah. Kramer (1996) mengatakan bahwa amplitudo gerakan tanah akan berkurang secara eksponensial menurut jarak $\mathrm{R}$

- Parameter gerakan tanah juga akan dipengaruhi oleh mekanisme sumber gempa (source mechanism) yang ditunjuukan oleh jenis patahan (fault types).

d. Beberapa macam atenuasi :

- $\quad$ McGuire, 1977

$$
\mathrm{Y}=472.10^{0.278 . \mathrm{M}} \cdot(\mathrm{R}+25)^{-1.301}
$$

- Iddris, 1991

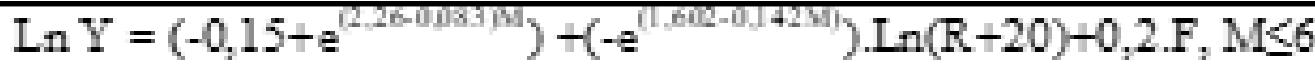

$$
\begin{aligned}
& \mathrm{F}=0,0,5 \text { dan } 1 \text { untuk strike -slip, oblique dan reverse-slip }
\end{aligned}
$$

- Campbel, 1989

$$
\operatorname{Ln} \mathrm{Y}=-2.501+0.623 . \mathrm{M}_{\mathrm{L}}-\mathrm{Ln}(\mathrm{R}+7,28)
$$

- Ambraseys, 1995

$$
\log \mathrm{Y}=-1,09+0,238 \mathrm{Ms}-0,0005 \cdot \mathrm{r}-\log \mathrm{r}, \mathrm{r}^{2}=\mathrm{R}^{2}+6^{2}, \mathrm{M}<7,4
$$

\begin{tabular}{|r|r|r|}
\hline \multicolumn{4}{|c|}{ McGuire, 1977 } \\
\hline M & $=$ & 6 \\
\hline \multicolumn{3}{|c|}{ Campbell, 1989 } \\
\hline M & $=$ & 6 \\
\hline F & $=$ & 1 \\
\hline \multicolumn{3}{|c|}{ Idriss, 1991 } \\
\hline M & $=$ & 1 \\
\hline F & $=$ & 0 \\
\hline \multicolumn{3}{|c|}{ Ambraseys, 1995 } \\
\hline M & $=$ & 6 \\
\hline
\end{tabular}




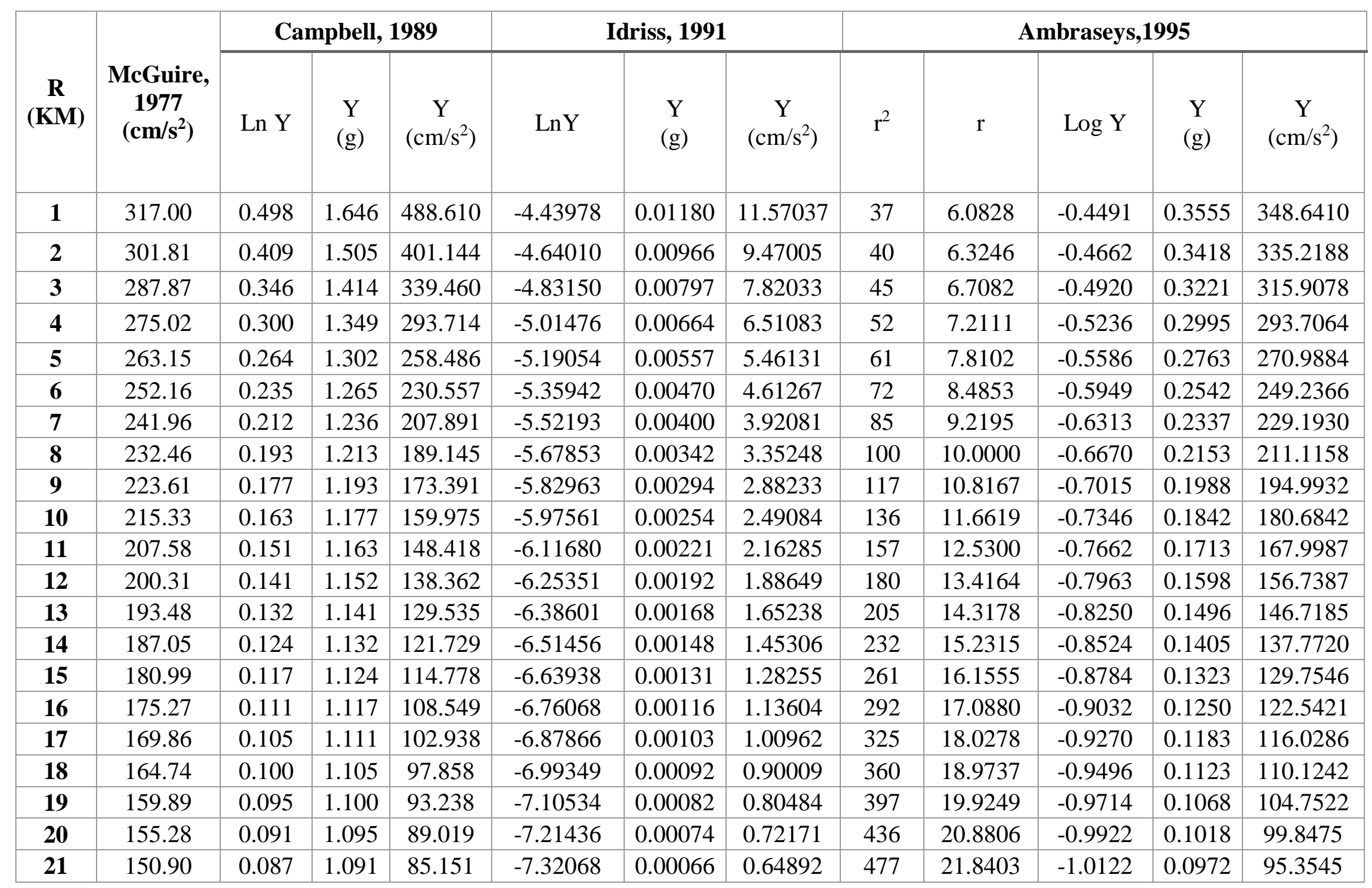




\begin{tabular}{|c|c|c|c|c|c|c|c|c|c|c|c|c|}
\hline 22 & 146.74 & 0.083 & 1.087 & 81.593 & -7.42445 & 0.00060 & 0.58496 & 520 & 22.8035 & -1.0314 & 0.0930 & 91.2257 \\
\hline 23 & 142.77 & 0.080 & 1.083 & 78.310 & -7.52577 & 0.00054 & 0.52859 & 565 & 23.7697 & -1.0499 & 0.0891 & 87.4202 \\
\hline 24 & 138.99 & 0.077 & 1.080 & 75.271 & -7.62476 & 0.00049 & 0.47877 & 612 & 24.7386 & -1.0677 & 0.0856 & 83.9026 \\
\hline 25 & 135.39 & 0.074 & 1.077 & 72.450 & -7.72153 & 0.00044 & 0.43461 & 661 & 25.7099 & -1.0850 & 0.0822 & 80.6427 \\
\hline 26 & 131.95 & 0.071 & 1.074 & 69.825 & -7.81617 & 0.00040 & 0.39537 & 712 & 26.6833 & -1.1016 & 0.0791 & 77.6138 \\
\hline 27 & 128.65 & 0.069 & 1.071 & 67.377 & -7.90877 & 0.00037 & 0.36040 & 765 & 27.6586 & -1.1177 & 0.0763 & 74.7929 \\
\hline 28 & 125.50 & 0.066 & 1.069 & 65.088 & -7.99943 & 0.00034 & 0.32916 & 820 & 28.6356 & -1.1332 & 0.0736 & 72.1599 \\
\hline 29 & 122.49 & 0.064 & 1.066 & 62.944 & -8.08821 & 0.00031 & 0.30120 & 877 & 29.6142 & -1.1483 & 0.0711 & 69.6970 \\
\hline 30 & 119.60 & 0.062 & 1.064 & 60.931 & -8.17521 & 0.00028 & 0.27610 & 936 & 30.5941 & -1.1629 & 0.0687 & 67.3885 \\
\hline 31 & 116.83 & 0.060 & 1.062 & 59.038 & -8.26047 & 0.00026 & 0.25354 & 997 & 31.5753 & -1.1771 & 0.0665 & 65.2207 \\
\hline 32 & 114.17 & 0.058 & 1.060 & 57.255 & -8.34409 & 0.00024 & 0.23320 & 1060 & 32.5576 & -1.1909 & 0.0644 & 63.1814 \\
\hline 33 & 111.61 & 0.057 & 1.058 & 55.572 & -8.42611 & 0.00022 & 0.21484 & 1125 & 33.5410 & -1.2043 & 0.0625 & 61.2596 \\
\hline 34 & 109.16 & 0.055 & 1.057 & 53.982 & -8.50660 & 0.00020 & 0.19822 & 1192 & 34.5254 & -1.2174 & 0.0606 & 59.4456 \\
\hline 35 & 106.80 & 0.054 & 1.055 & 52.476 & -8.58561 & 0.00019 & 0.18316 & 1261 & 35.5106 & -1.2301 & 0.0589 & 57.7308 \\
\hline 36 & 104.53 & 0.052 & 1.053 & 51.049 & -8.66319 & 0.00017 & 0.16949 & 1332 & 36.4966 & -1.2425 & 0.0572 & 56.1074 \\
\hline 37 & 102.34 & 0.051 & 1.052 & 49.695 & -8.73941 & 0.00016 & 0.15705 & 1405 & 37.4833 & -1.2546 & 0.0556 & 54.5684 \\
\hline 38 & 100.23 & 0.049 & 1.051 & 48.408 & -8.81430 & 0.00015 & 0.14572 & 1480 & 38.4708 & -1.2664 & 0.0542 & 53.1073 \\
\hline 39 & 98.20 & 0.048 & 1.049 & 47.183 & -8.88790 & 0.00014 & 0.13538 & 1557 & 39.4588 & -1.2779 & 0.0527 & 51.7186 \\
\hline 40 & 96.24 & 0.047 & 1.048 & 46.017 & -8.96027 & 0.00013 & 0.12593 & 1636 & 40.4475 & -1.2891 & 0.0514 & 50.3971 \\
\hline 41 & 94.34 & 0.046 & 1.047 & 44.904 & -9.03145 & 0.00012 & 0.11728 & 1717 & 41.4367 & -1.3001 & 0.0501 & 49.1380 \\
\hline 42 & 92.52 & 0.045 & 1.046 & 43.842 & -9.10147 & 0.00011 & 0.10935 & 1800 & 42.4264 & -1.3108 & 0.0489 & 47.9370 \\
\hline 43 & 90.75 & 0.044 & 1.045 & 42.827 & -9.17036 & 0.00010 & 0.10207 & 1885 & 43.4166 & -1.3214 & 0.0477 & 46.7904 \\
\hline 44 & 89.04 & 0.043 & 1.044 & 41.857 & -9.23818 & 0.00010 & 0.09537 & 1972 & 44.4072 & -1.3317 & 0.0466 & 45.6945 \\
\hline 45 & 87.39 & 0.042 & 1.043 & 40.927 & -9.30494 & 0.00009 & 0.08922 & 2061 & 45.3982 & -1.3417 & 0.0455 & 44.6460 \\
\hline 46 & 85.79 & 0.041 & 1.042 & 40.037 & -9.37068 & 0.00009 & 0.08354 & 2152 & 46.3897 & -1.3516 & 0.0445 & 43.6420 \\
\hline 47 & 84.25 & 0.040 & 1.041 & 39.182 & -9.43543 & 0.00008 & 0.07830 & 2245 & 47.3814 & -1.3613 & 0.0435 & 42.6797 \\
\hline
\end{tabular}




\begin{tabular}{|c|c|c|c|c|c|c|c|c|c|c|c|c|}
\hline 48 & 82.75 & 0.039 & 1.040 & 38.362 & -9.49922 & 0.00007 & 0.07346 & 2340 & 48.3735 & -1.3708 & 0.0426 & 41.7567 \\
\hline 49 & 81.30 & 0.038 & 1.039 & 37.575 & -9.56208 & 0.00007 & 0.06899 & 2437 & 49.3660 & -1.3801 & 0.0417 & 40.8705 \\
\hline 50 & 79.89 & 0.038 & 1.038 & 36.817 & -9.62404 & 0.00007 & 0.06484 & 2536 & 50.3587 & -1.3893 & 0.0408 & 40.0190 \\
\hline 51 & 78.52 & 0.037 & 1.037 & 36.089 & -9.68512 & 0.00006 & 0.06100 & 2637 & 51.3517 & -1.3982 & 0.0400 & 39.2003 \\
\hline 52 & 77.20 & 0.036 & 1.037 & 35.388 & -9.74534 & 0.00006 & 0.05743 & 2740 & 52.3450 & -1.4070 & 0.0392 & 38.4125 \\
\hline 53 & 75.91 & 0.035 & 1.036 & 34.712 & -9.80474 & 0.00006 & 0.05412 & 2845 & 53.3385 & -1.4157 & 0.0384 & 37.6539 \\
\hline 54 & 74.67 & 0.035 & 1.035 & 34.060 & -9.86332 & 0.00005 & 0.05104 & 2952 & 54.3323 & -1.4242 & 0.0377 & 36.9229 \\
\hline 55 & 73.46 & 0.034 & 1.035 & 33.432 & -9.92112 & 0.00005 & 0.04818 & 3061 & 55.3263 & -1.4326 & 0.0369 & 36.2181 \\
\hline 56 & 72.28 & 0.033 & 1.034 & 32.826 & -9.97816 & 0.00005 & 0.04551 & 3172 & 56.3205 & -1.4408 & 0.0362 & 35.5381 \\
\hline 57 & 71.13 & 0.033 & 1.033 & 32.240 & -10.03444 & 0.00004 & 0.04301 & 3285 & 57.3149 & -1.4489 & 0.0356 & 34.8815 \\
\hline 58 & 70.02 & 0.032 & 1.033 & 31.674 & -10.09000 & 0.00004 & 0.04069 & 3400 & 58.3095 & -1.4569 & 0.0349 & 34.2473 \\
\hline 59 & 68.94 & 0.032 & 1.032 & 31.127 & -10.14486 & 0.00004 & 0.03852 & 3517 & 59.3043 & -1.4647 & 0.0343 & 33.6343 \\
\hline 60 & 67.88 & 0.031 & 1. & 30 & -10.19902 & 0.0 & 0. & 3636 & 2993 & 25 & 337 & 33 \\
\hline 61 & 66.86 & 0.031 & 1.031 & 30.085 & -10.25251 & 0.00004 & 0.03459 & 3757 & 61.2944 & -1.4801 & 0.0331 & 32.4678 \\
\hline 62 & 65.86 & 0.030 & 1.031 & 29.589 & -10.30535 & 0.00003 & 0.03281 & 3880 & 62.2896 & -1.4876 & 0.0325 & 31.9124 \\
\hline 63 & 64.89 & 0.030 & 1.030 & 29.108 & -10.35754 & 0.00003 & 0.03114 & 4005 & 63.2851 & -1.4949 & 0.0320 & 31.3745 \\
\hline 64 & 63.94 & 0.029 & 1.030 & 28.642 & -10.40911 & 0.00003 & 0.02957 & 4132 & 64.2806 & -1.5022 & 0.0315 & 30.8532 \\
\hline 65 & 63.02 & 0.029 & 1.029 & 28.190 & -10.46007 & 0.00003 & 0.02810 & 4261 & 65.2763 & -1.5094 & 0.0309 & 30.3478 \\
\hline 66 & 62.12 & 0.028 & 1.029 & 27.752 & -10.51043 & 0.00003 & 0.02672 & 4392 & 66.2722 & -1.5165 & 0.0304 & 29.8575 \\
\hline 67 & 61.24 & 0.028 & 1.028 & 27.326 & -10.56021 & 0.00003 & 0.02543 & 4525 & 67.2681 & -1.5234 & 0.0300 & 29.3817 \\
\hline 68 & 60.39 & 0.027 & 1.028 & 26.913 & -10.60942 & 0.00002 & 0.02421 & 4660 & 68.2642 & -1.5303 & 0.0295 & 28.9198 \\
\hline 69 & 59.55 & 0.027 & 1.027 & 26.512 & -10.65808 & 0.00002 & 0.02306 & 4797 & 69.2604 & -1.5371 & 0.0290 & 28.4712 \\
\hline 70 & 58.74 & 0.027 & 1.027 & 26.121 & -10.70619 & 0.00002 & 0.02197 & 4936 & 70.2567 & -1.5438 & 0.0286 & 28.0353 \\
\hline 71 & 57.94 & 0.026 & 1.027 & 25.742 & -10.75377 & 0.00002 & 0.02095 & 5077 & 71.2531 & -1.5504 & 0.0282 & 27.6115 \\
\hline
\end{tabular}




\begin{tabular}{|c|c|c|c|c|c|c|c|c|c|c|c|c|}
\hline 72 & 57.17 & 0.026 & 1.026 & 25.373 & -10.80083 & 0.00002 & 0.01999 & 5220 & 72.2496 & -1.5570 & 0.0277 & 27.1995 \\
\hline 73 & 56.41 & 0.026 & 1.026 & 25.015 & -10.84738 & 0.00002 & 0.01908 & 5365 & 73.2462 & -1.5634 & 0.0273 & 26.7986 \\
\hline 74 & 55.67 & 0.025 & 1.025 & 24.666 & -10.89344 & 0.00002 & 0.01822 & 5512 & 74.2428 & -1.5698 & 0.0269 & 26.4086 \\
\hline 75 & 54.95 & 0.025 & 1.025 & 24.326 & -10.93900 & 0.00002 & 0.01741 & 5661 & 75.2396 & -1.5761 & 0.0265 & 26.0288 \\
\hline 76 & 54.24 & 0.024 & 1.025 & 23.994 & -10.98409 & 0.00002 & 0.01664 & 5812 & 76.2365 & -1.5823 & 0.0262 & 25.6590 \\
\hline 77 & 53.55 & 0.024 & 1.024 & 23.672 & -11.02871 & 0.00002 & 0.01592 & 5965 & 77.2334 & -1.5884 & 0.0258 & 25.2987 \\
\hline 78 & 52.87 & 0.024 & 1.024 & 23.358 & -11.07288 & 0.00002 & 0.01523 & 6120 & 78.2304 & -1.5945 & 0.0254 & 24.9477 \\
\hline 79 & 52.21 & 0.024 & 1.024 & 23.051 & -11.11659 & 0.00001 & 0.01458 & 6277 & 79.2275 & -1.6005 & 0.0251 & 24.6054 \\
\hline 80 & 51.57 & 0.023 & 1.023 & 22.752 & -11.15987 & 0.00001 & 0.01396 & 6436 & 80.2247 & -1.6064 & 0.0248 & 24.2717 \\
\hline 81 & 50.94 & 0.023 & 1.023 & 22.461 & -11.20272 & 0.00001 & 0.01337 & 6597 & 81.2219 & -1.6123 & 0.0244 & 23.9462 \\
\hline 82 & 50.32 & 0.023 & 1.023 & 22.177 & -11.24514 & 0.00001 & 0.01282 & 6760 & 82.2192 & -1.6181 & 0.0241 & 23.6286 \\
\hline 83 & 49.71 & 0.022 & 1.023 & 21.899 & -11.28715 & 0.00001 & 0.01229 & 6925 & 83.2166 & -1.6238 & 0.0238 & 23.3186 \\
\hline 84 & 49.12 & 0.022 & 1. & 21.628 & 75 & 0.00 & 0.0 & 7092 & 84.2140 & -1.6295 & 235 & 23 \\
\hline 85 & 48.54 & 0.022 & 1.022 & 21.363 & -11.36996 & 0.00001 & 0.01131 & 7261 & 85.2115 & -1.6351 & 0.0232 & 22.7204 \\
\hline 86 & 47.97 & 0.022 & 1.022 & 21.105 & -11.41077 & 0.00001 & 0.01086 & 7432 & 86.2090 & -1.6407 & 0.0229 & 22.4318 \\
\hline 87 & 47.41 & 0.021 & 1.021 & 20.852 & -11.45120 & 0.00001 & 0.01043 & 7605 & 87.2067 & -1.6462 & 0.0226 & 22.1497 \\
\hline 88 & 46.87 & 0.021 & 1.021 & 20.605 & -11.49126 & 0.00001 & 0.01002 & 7780 & 88.2043 & -1.6516 & 0.0223 & 21.8740 \\
\hline 89 & 46.33 & 0.021 & 1.021 & 20.364 & -11.53095 & 0.00001 & 0.00963 & 7957 & 89.2020 & -1.6570 & 0.0220 & 21.6045 \\
\hline 90 & 45.81 & 0.021 & 1.021 & 20.128 & -11.57027 & 0.00001 & 0.00926 & 8136 & 90.1998 & -1.6623 & 0.0218 & 21.3410 \\
\hline 91 & 45.30 & 0.020 & 1.020 & 19.898 & -11.60924 & 0.00001 & 0.00891 & 8317 & 91.1976 & -1.6676 & 0.0215 & 21.0833 \\
\hline 92 & 44.80 & 0.020 & 1.020 & 19.672 & -11.64786 & 0.00001 & 0.00857 & 8500 & 92.1954 & -1.6728 & 0.0212 & 20.8312 \\
\hline 93 & 44.30 & 0.020 & 1.020 & 19.451 & -11.68613 & 0.00001 & 0.00825 & 8685 & 93.1933 & -1.6780 & 0.0210 & 20.5844 \\
\hline 94 & 43.82 & 0.020 & 1.020 & 19.235 & -11.72407 & 0.00001 & 0.00794 & 8872 & 94.1913 & -1.6831 & 0.0207 & 20.3430 \\
\hline 95 & 43.34 & 0.019 & 1.020 & 19.023 & -11.76168 & 0.00001 & 0.00765 & 9061 & 95.1893 & -1.6882 & 0.0205 & 20.1066 \\
\hline
\end{tabular}




\begin{tabular}{|c|c|c|c|c|c|c|c|c|c|c|c|c|}
\hline $\mathbf{9 6}$ & 42.88 & 0.019 & 1.019 & 18.816 & -11.79896 & 0.00001 & 0.00737 & 9252 & 96.1873 & -1.6932 & 0.0203 & 19.8751 \\
\hline $\mathbf{9 7}$ & 42.42 & 0.019 & 1.019 & 18.613 & -11.83592 & 0.00001 & 0.00710 & 9445 & 97.1854 & -1.6982 & 0.0200 & 19.6484 \\
\hline $\mathbf{9 8}$ & 41.97 & 0.019 & 1.019 & 18.414 & -11.87257 & 0.00001 & 0.00684 & 9640 & 98.1835 & -1.7031 & 0.0198 & 19.4263 \\
\hline $\mathbf{9 9}$ & 41.53 & 0.019 & 1.019 & 18.220 & -11.90891 & 0.00001 & 0.00660 & 9837 & 99.1817 & -1.7080 & 0.0196 & 19.2087 \\
\hline $\mathbf{1 0 0}$ & 41.10 & 0.018 & 1.019 & 18.029 & -11.94494 & 0.00001 & 0.00637 & 10036 & 100.1798 & -1.7129 & 0.0194 & 18.9955 \\
\hline
\end{tabular}

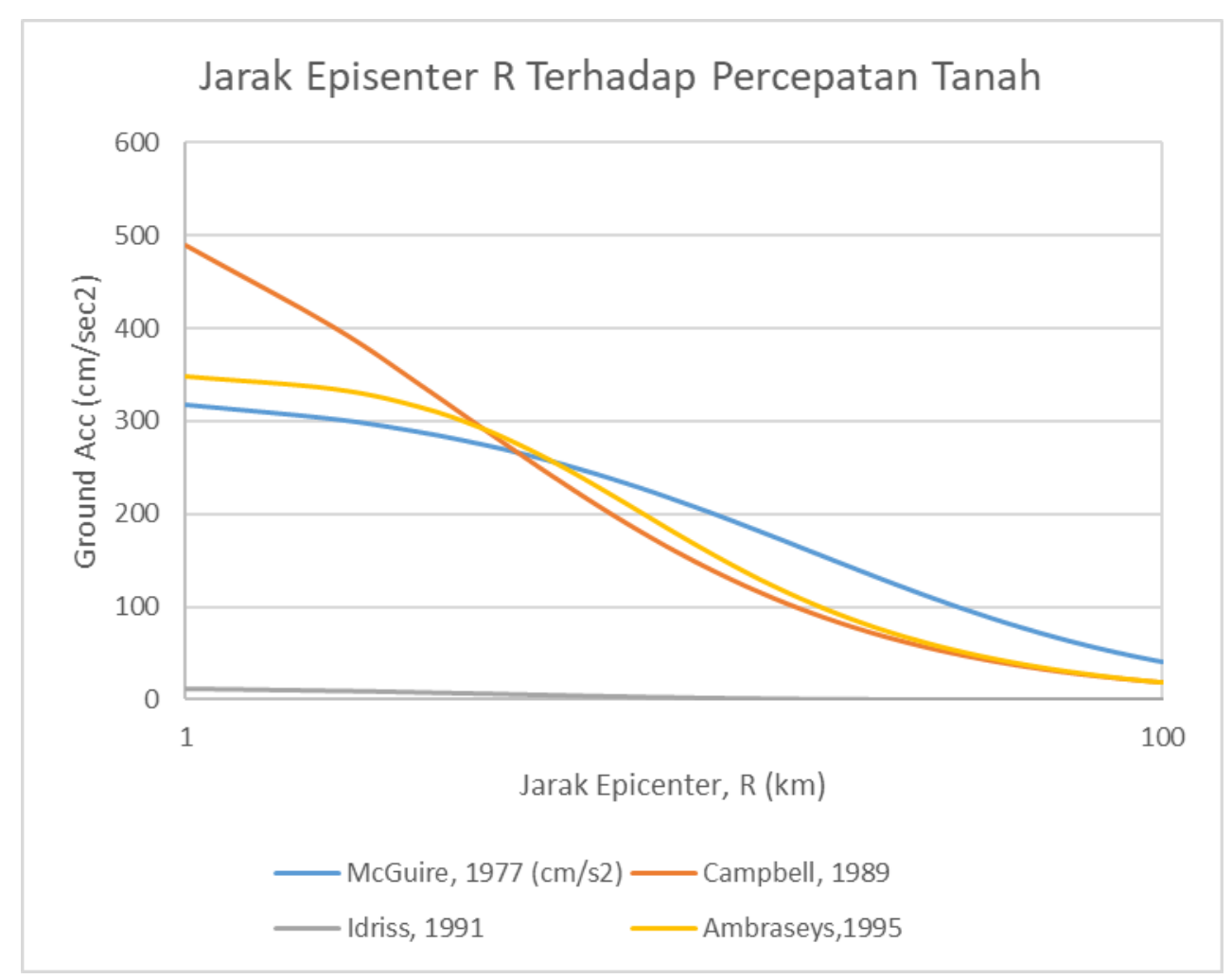




\section{Tujuan}

Penelitian ini bertujuan untuk menganalisis pengaruh antara jarak terhadap percepatan tanah dengan membandingkan fungsi atenuasi Mc Guire (1977), Campbell (1981), Idriss (1991) dan Ambraseys (1995).

\section{Kesimpulan}

Dari ketiga grafik diatas dapat disimpulkan bahwa nilai ground acc akan semakin kecil terhadap jarak epicenter. Hal ini sesuai dengan factor yang mempengaruhi atenuasi salah satunya yaitu jarak ke site (jarak episenter, jarak terdetak, jarak hiposenter).

\section{Daftar Pustaka}

Widodo, 2012, Seismologi Teknik \& Rekayasa Kegempaan, Pustaka Pelajar, Yogyakarta http://yohannachristiani.blogspot.com/2012/06/fungsi-atenuasi.html Saputro, I. T. (2018, June 6). ANALISIS PERBANDINGAN KURVA HAZARD PADA KOTA BANDA ACEH DENGAN SUMBER GEMPA SESAR SEULIMEUM DAN MENGGUNAKAN BEBERAPA FUNGSI ATENUASI.

https://doi.org/10.31227/osf.io/uvp2y 